\title{
Chapter 9 \\ Why a Species-Based Approach to Biodiversity Is Not Enough. Lessons from Multispecies Biofilms
}

\author{
Jorge Marques da Silva and Elena Casetta
}

\begin{abstract}
In recent years, we have assisted to an impressive effort to identify and catalogue biodiversity at the microbial level across a wide range of environments, human bodies included (e.g., skin, oral cavity, intestines). This effort, fostered by the decreasing cost of DNA sequencing, highlighted not only the vast diversity at the microbial level but also the importance of cells' social interactions, potentially leading to the emergence of novel diversity. In this contribution, we shall argue that entities other than species, and in particular multispecies biofilms, might play a crucial — and still underestimated — role in increasing biodiversity as well as in conserving it. In particular, after having discussed how microbial diversity impacts ecosystems (Sect. 9.1), we argue (Sect. 9.2) that multispecies biofilms may increase biodiversity at both the genetic and phenotypic level. In Sect. 9.3 we discuss the possibility that multispecies biofilms, both heterotrophic and autotrophic, are evolutionary individuals, i.e. units of selection. In the conclusion, we highlight a major limitation of the traditional species-based approach to biodiversity origination and conservation.
\end{abstract}

Keywords Microbial diversity $\cdot$ Biofilms $\cdot$ Biological individuality

\subsection{Microbial Biodiversity and Bacterial Modes of Living}

Microbial biodiversity is essential for life and conserving it shall be a primary concern both to sustain human health and ecosystems wellbeing. As a matter of facts, microbial biodiversity decisively affects the functioning of ecosystems (Falkowski

\footnotetext{
J. Marques da Silva

BioISI - Biosystems and Integrative Sciences Institute and Department of Plant Biology,

Faculdade de Ciências, Universidade de Lisboa, Lisboa, Portugal

e-mail: jmlsilva@fc.ul.pt

E. Casetta $(\bowtie)$

Department of Philosophy and Education, University of Turin, Turin, Italy

e-mail: elena.casetta@unito.it
}

E. Casetta et al. (eds.), From Assessing to Conserving Biodiversity, 
et al. 2008; van der Heijden et al. 2008), being largely responsible for their metabolism and biomass. Microbes set the level of primary production, drive decomposition and convert organic matter so that it can be used by plants, and contribute to climate regulation. Moreover, microbial biodiversity is fundamental in sustainable development, in virtue of its industrial and commercial applications such as, for instance, sustainable removal of chemical pollutants from the environment, or the employment of bacteria as pesticides (Qaim and Zilberman 2003). In terms of ecosystem services, its value is enormous.

On the basis of FAO's data, the economic value of microbial functions, once converted in terms of the ecosystem services microbial diversity contributes to, amounts to 500 billion US\$ per year for soil formation on agricultural land; 90 for nitrogen fixation for agriculture; 42.5 for pharmaceuticals; 1.3 for the synthesis of industrial enzymes (Table 9.1, Bell et al. 2009: 125). But the involvement of microbes in ecosystem functioning, and in every aspect of our life is so pervasive and so intimate that it is probably impossible not to underestimate the value-the monetary value as well- of microbial diversity.

In spite of its pivotal importance, the role of biodiversity at the microbial level is usually ignored in the debates concerning the so-called biodiversity crisis as well as by conservation policies and actions, mainly centred on animals and plants. Yet, the total biomass of bacteria and archaea has been estimated to equate that of terrestrial and marine plants, making microbes the largest unexplored reservoir of biodiversity on earth (Whitman et al. 1998). To get an idea, think that each millilitre of water in oligotrophic environments, such as deep oceans or deep subsurfaces, contains approximately $1 \times 10^{5}$ bacterial cells, most of them in a dormant starving state (Kjelleberg 1993) and that each gram of soil contains between 2000 and 8.3 million species of bacteria (Roesch et al. 2007).

Among the reasons for this neglect there is, of course, the fact that microbes are far less appealing than charismatic taxa such as the giant panda or the Siberian tiger, and policies based on the motto "save the Bacillus thuringiensis" must not sound very catchy to a politician looking for votes. ${ }^{1}$ Besides political reasons, there are difficulties connected with the assessment of microbial biodiversity. Firstly, most microbial strains are difficult to be cultured in the laboratory. Secondly, microbes typically live as interacting communities, and the number of individual bacteria to identify is simply too large to permit a proper survey of the composition of the community (think that a poor environment such as drinking water has thousands of microbial individuals per millilitre). As a consequence, the diversity of microbial communities is still largely unknown (Bell et al. 2009). Thirdly, the majority of microbial communities are multispecies communities, and there is an ongoing controversy in settling how these species should be defined and identified (Doolittle and

\footnotetext{
${ }^{1}$ And yet, the usefulness of Bacillus thuringiensis is well recognised, since some of its strains, during sporulation, produce toxins. These toxins target insects' larvae, acting as a natural insecticide; and they do not target humans, hence being — unlike the majority of artificial pesticides—relatively innocuous. (A more controversial matter is, of course, the use of Bacillus thuringiensis genes in GM crops, such as Bt corn.)
} 
Papke 2006; Achtman and Wagner 2008; Ereshefsky 2010; O'Malley 2014). ${ }^{2}$ Setting aside the unresolved theoretical aspects of the problem, which are not of our concern here, microbial species are normally recognised amongst microbiologists, at least for practical purposes, and expressions like "multispecies community" and "multispecies biofilm" are commonly used. For instance, a convention is largely adopted that two individual microbes are of the same species when they share an arbitrary degree of DNA sequence similarity-often, $97 \%$ is taken as the threshold (Bell et al. 2009: 124).

As said, microorganisms rarely live alone; more typically they live in communities. When such communities comprise a thin layer of cells irreversibly adhering to a (biotic or abiotic) surface or interface and produce a matrix of slime-like extracellular polymeric substances (EPS) - mainly polysaccharides, proteins and nucleic acids - in which they become embedded, they are called "biofilms". They can include microorganisms of just one kind (monospecies biofilms) or they can be composedand more often so- of different species of bacteria, or even of different types of microorganism, both prokaryotic (bacteria, archaea) and eukaryotic (fungi, protists, algae) (Besemer 2015). Biofilms are the major mode of microbial life (Nadell et al. 2016), and multispecies biofilms are the dominant form in nature (Elias and Banin 2012). They "might lack the grandeur of a tropical rain-forest, but not their complexity, or their significance in terms of ecosystem function" (Hansen et al. 2007a).

In several cases biofilms are enemies hard to destroy, being more resistant to antibiotic treatments than bacteria at the planktonic state (as, for instance, is the case for oral biofilms or Pseudomonas aeruginosa biofilms which infect lungs of cysticfibrosis-affected patients). In other cases, they play a crucial role for ecosystem functioning, contributing substantially to biogeochemical processes and to the maintenance and promotion of biodiversity. To show their role in general ecosystem maintenance and in promoting biodiversity — not only at the microbial level but also at the macrobial level, such as plants or animals - the example of plants' biofilms is illuminating.

Plant surfaces and the rhizosphere are rich of multispecies biofilms, which grow attached to plants' transport vessels, stems, leaves, and roots, helping maintain biodiversity both at the microbial and at the plants' level. One way they help conserve biodiversity at the microbial level is by ensuring the survival of bacteria they are made of in harsh environments (Angus and Hirsch 2013; Bogino et al. 2013). In fact, bacteria that compound the biofilm are provided by the EPS with a protection that they do not have in their planktonic state. EPS protects them against environmental stress factors, allowing them to better face fluctuating environmental conditions such as desiccation, changes in $\mathrm{pH}$ or in temperature, or scarce availability of nutrients, which may derive both from casualties and from human activities, for instance

\footnotetext{
${ }^{2}$ This is part and parcel of the so-called "species problem" (see for instance Richards 2010), i.e. the problem of defining, delimiting, and identifying species. These tasks are particularly controversial when asexually reproducing organisms - like a large part of microorganisms - are at issue; partisans of the biological species concept such as Dobzhansky (1937) and Mayr (1970), for instance, simply claim that asexually reproducing organisms do not form species at all.
} 
as a consequence of climate change or deforestation. Biofilms have also effects on plants' health and productivity (of course, depending on the kind of biofilms, these effects can be beneficial or detrimental to the host plant). For instance, certain bacteria in the EPS matrix seem not only to improve biocontrol-i.e. the protection of plants from phytopathogens - but also stimulate plant growth by secreting specific hormones and by means of a variety of other mechanisms, hence representing sustainable alternatives to agrochemicals (Bogino et al. 2013; Lugtenberg et al. 2013). In short, "biofilms have been shown to enhance not only the fitness of individual bacteria but also plant health and productivity as a result of the cumulative selective advantage of the individual bacteria" (Bogino et al. 2013, p. 15849).

To generalise, at the ecosystem's level, a fundamental functional role is played by two kinds of multispecies autotrophic biofilms (i.e. multispecies biofilms which are able to synthesise their own organic food from inorganic substances - opposite to heterotrophic biofilms, which depend on other organisms or on dead organic matter for food, since they do not synthesise their own food), namely aquatic photosynthetic multispecies biofilms and land biological soil crusts (BSCs), which we shall discuss in more detail in Sect. 9.3. Photosynthetic biofilms form the basis of trophic chains in many aquatic environments, as is the case with diatom (a major group of microalgae)-dominated intertidal microphytobenthos (MPB) on estuaries (Macintyre et al. 1996). The EPS produced by MPB diatoms promote the aggregation of sediment particles and therefore crucially impact the stabilisation of estuarine intertidal mudflats (Paterson and Black 1999). A similar ecological role in terrestrial ecosystems is played by the EPS produced by the cyanobacteria of BSCs (Eldridge and Leys 2003; Adessi et al. 2018).

MPB are diatom-dominated communities that cover estuarine mudflats (epipelic MPB) and sandbanks (epipsamic MPB). Epipelic MPB is particularly relevant for ecosystem functioning, as it is largely responsible for the high primary productivity of intertidal mudflats, which in turn are important components of estuarine productivity (Underwood and Kromkamp 1999 - in Stal and de Brouwer 2003). This intertidal microphytobenthos living on soft-sediment habitats is composed mostly of motile diatoms exhibiting rhythmic vertical migrations across the photic zone (i.e. the uppermost layer) of the sediment in close synchronisation with tidal and day/ night cycles (Round and Palmer 1966; Paterson 1986). It should also be mentioned that the hidden beauty of MPB communities has been praised by biologists (Marques da Silva 2015), who referred to them as "the secret gardens" (Macintyre et al. 1996) since under the microscope lens they reveal unexpected beauty. In addition to their indisputable ecological role then, a further contribution to biodiversity can be highlighted for MPB, namely their aesthetic value - an item included amongst ecosystem services (for instance by Costanza et al. 1997, p. 254, who refer to "aesthetic, artistic, educational, spiritual, and/or scientific values").

Diatoms, just like bacteria, excrete EPS which are believed to contribute to the cohesion of intertidal mudflats (Paterson and Black 1999). MPB are then biofilms in their own right, as cells occupy a thin layer over the surface of a substrate, and they are immersed in an EPS matrix produced by them-the two requirements to classify a microbial community as a biofilm (as seen above). They are multispecies, eukaryotic-dominated, photosynthetic biofilms. 
A similar ecological role is played, in terrestrial ecosystems, by the EPS produced by the cyanobacteria of biological soil crusts (Eldridge and Leys 2003). Biological soil crusts are complex assemblages of cyanobacteria and other bacteria, green algae, mosses, microfungi, lichens. Cyanobacterial filaments and fungal hyphae (and sometimes also lichen and moss rhizoids), present on the few top millimetres of soil, stick together loose particles, making a matrix that stabilises and protects the soil surface from the erosive forces of wind and rainfall. They also function as living mulch by retaining soil moisture (Adessi et al. 2018) and discouraging annual weed growth. Although compositionally diverse, these crusts occur in all arid and semi-arid regions, where they occupy the nutrient-poor zones between vegetation clumps in many types of arid-land vegetation. In some plant communities, they may constitute up to $70 \%$ of the living cover, fixing atmospheric nitrogen and significantly contributing to soil's organic matter. Yet, biological soil crusts have only recently been recognised as having a key influence on terrestrial ecosystems. Their role on biodiversity is also significant because, in arid and semi-arid communities, there are often many more species associated with the biological soil crusts at a given site than there are vascular plants (Belnap et al. 2001 and references therein). Bare soil is initially colonised by cyanobacteria. Later, if the environmental conditions are favourable, ecological succession may progress to more structurally complex biological crusts, forming a rough, uneven carpet or skin of low stature (1-10 cm in height) dominated by bryophytes (i.e. non-vascular land plants). Here we will focus mainly on cyanobacteria-dominated BSCs, common on early successional stages of soil colonisation. Although rarely defined as biofilms, these crusts meet the criteria for being biofilms: they exist as a thin layer at the interface between soil and air and are embedded in a matrix formed by the cyanobacteria-produced EPS.

\subsection{How Multispecies Biofilms Increase Phenotypic and Genetic Diversity}

Besides contributing to the maintenance of biodiversity at macrobial levels of biological organisation, there are several ways in which multispecies biofilms increase biodiversity at the microbial level and help maintain it. In this section, we shall see how they increase phenotypic and genetic diversity. Then, in Sect. 9.3, we are going to argue that, in virtue of being putative evolutionary individuals they, first, prompt a general reflection on the processes originating biodiversity and, secondly, highlight some limits of the species-based approach to biodiversity conservation.

Phenotypic diversity is the diversity of phenotypes in a population. Biofilms promote the emergence of new microbial phenotypes, increasing, as we are going to show, biodiversity both at the level of the monospecies colony and at the biofilm level. Being related to different fitness values in a population, phenotypic diversity is crucial for the survival and possible evolution of a species. According to some, "phenotypic diversity is the most important aspect of biodiversity, at least in terms of evolution by natural selection of organisms" (Woods 2000, p. 44ff). To under- 
stand how and why biofilms promote phenotypic diversity, we need to briefly illustrate how they form.

Biofilm formation is a complex process typically including 5 phases. The first phase is primary adhesion, namely the initial—and reversible — attachment of cells to a surface or an interface. It is worth noting that because of the small size of bacterial cells, gravity plays a negligible role, and the approach of cells to substrates is mostly due to their motility. When cells come close to the substrate, the balance between attraction and repulsion forces will dictate the occurrence of primary adhesion. In primary adhesion, binding is still reversible. The second phase is irreversible adhesion. If cells come closer to the substrate $(1.5 \mathrm{~nm})$, ionic, covalent and hydrogen bonds come into play and cells enter secondary adhesion; the binding becomes permanent. It is at this stage that the production of extracellular polymeric substances increases. EPS, strengthening the link between cells and substrate, provides the biofilm with a structural support (in a way that may remind us of animals' and plants' extracellular matrix). In the third and fourth phase, the architecture of the biofilm develops and the biofilm reaches maturity. Biofilm maturation changes the conditions within the environment that surrounds the microorganisms in terms of cell population density, $\mathrm{pH}$, oxygen and the presence of micronutrients. In turn, microenvironment diversity causes local environmental adaptation, producing physiological heterogeneity in the biofilm. It has been shown that in Pseudomonas aeruginosa biofilms, the cells at the top had high mRNA abundance for genes involved in general metabolic functions, whereas the cells at the bottom had low mRNA abundance for housekeeping genes. Accordingly, cells at the top were actively dividing, whereas cells at the bottom showed a low division rate, possibly due to a long-term exposition to a totally depleted level of oxygen (Williamson et al. 2012). Vlamakis et al. (2008) showed that in Bacillus subtilis biofilms, motile, matrix-producing, and sporulating cells are located at distinct regions, and that the localisation and frequency of the different cell types are dynamic throughout the development of the biofilm. It has been suggested that sporulation is a culminating feature of biofilm formation, and that spore formation is coupled with the formation of an architecturally complex community of cells. Therefore, as a consequence of the heterogeneity of the microenvironment, a difference between reproductive and metabolic cells may arise (Cabarkapa et al. 2013; Kaplan 2010). The mature biofilm is a multicellular entity endowed with a complex internal structure, metabolism, and division of labour among its part. The structural adaptations and relations it shows "are made possible by the expressions of sets of genes that result in phenotypes that differ profoundly from those of planktonically grown cells of the same species" (Stoodley et al. 2002, p. 187). Gene regulation during biofilm development controls the switch from the planktonic state of cells to their biofilm state, making possible the growth of the biofilm itself (changes in phenotypic expression in response to growth strategies have been documented, see Stoodley et al. 2002). The fifth phase is detachment, e.g. the release of individual cells or clumps of cells from the biofilm.

As said, living in a biofilm promotes the emergence of new microbial phenotypes. For instance, in a study on Pseudomonas aeruginosa, Sauer et al. (2002) concluded that during biofilm development, $P$. aeruginosa cells display at least 
three different phenotypes: planktonic, mature biofilm, and dispersion (and the dispersion-phenotype looks more similar to the planktonic one than to the mature biofilm one), with different regulation of motility, production of alginate (a principal component of the EPS), and quorum sensing (i.e. a chemical communication system that "measures" population density and regulates gene expression accordingly).

Let us substantiate our claim by considering another concrete example that shows the emergence of a new phenotype in the monospecies colony in the biofilm, as well as in the whole multispecies biofilm. Hansen et al. (2007a, b) performed an experiment on Acinetobacter (widely-distributed in nature and commonly occurring in soil and water) and Pseudomonas putida (a soil bacterium that feeds on dead organic matter). When the two bacteria live in an environment where the only source of carbon is benzyl alcohol, they stay in a sort of host-commensal relation, since $P$. putida depends on Acinetobacter's partitioning benzyl alcohol in benzoate, that $P$. putida can metabolise. The experiment compared the behaviour of the bacteria first in a spatially unstructured chemostat environment (an apparatus to grow bacterial cultures at a constant rate), then on a glass surface within a biofilm flow chamber (a structure that allows direct microscopic investigation of biofilm formation; biofilms in flow chambers grow under hydrodynamic conditions, and the environment can be carefully controlled and easily changed). In the chemostat unstructured environment (i.e. at the planktonic state), the two species coexisted, but only at benzyl alcohol concentrations above $430 \mathrm{mM}$. On the glass surface, they coexisted at benzyl alcohol concentrations as low as about $130 \mathrm{mM}$. In other words, the spatial structure of the formed biofilm extended the range of resource concentrations over which the two species may survive. Looking at the biofilm's formation, Hansen et al. (2007a) observed that the structure of the biofilm after $24 \mathrm{~h}$ was characterised by discrete colonies of Acinetobacter surrounded by loose assemblages of $P$. putida and that the two species were spatially separated. But after 5 days the association changed: at separate focal points, $P$. putida grew in intimate contact with Acinetobacter, and after 5 further days, Acinetobacter colonies were covered by a layer of $P$. putida.

During the course of the biofilm's development, a rough phenotypic variant of $P$. putida colony (VP) emerged and was selected over the ancestral (wild-type) $P$. putida. While the new phenotype is a property of $P$. putida's cells, the ensuing variation determines the emergence of a new biofilm phenotype. To show this, we shall consider three differences between the two biofilm phenotypes: persistency, biomass, fitness. When compared to the phenotype of the biofilm with the P. putida wild-type (WTP), the phenotype of the biofilm with the P. putida variant (VP) displays (i) more persistency; (ii) more biomass (ecological productivity); (iii) a different fitness.

\section{(i) More persistency}

Because of the extensive consumption of oxygen to metabolise benzyl alcohol, the presence of oxygen in the biofilm environment decreases, and the "mantle" of the $P$. putida variant acts as a shield, preventing Acinetobacter-which is covered 
by it - from reaching oxygen. This stressful environment induces the $P$. putida new variant to produce a more resistant, cellulose-like polymer (EPS) that prevents the biofilm from dispersing. Hansen et al. (2007b) tested the response to oxygen starvation by inducing oxygen downshift (near to zero), with the result that, while the VP showed no dispersal, in the WTP's case the first signs of detachment appeared within minutes and almost the whole biofilm detached after $25 \mathrm{~min}$. The proposed explanation for the difference is that thanks, at least in part, to the more resistant EPS, the rough variant sticks robustly to Acinetobacter microcolonies (which, in turn, serve as an anchor point) ensuring them close access to the secreted benzoate. The production of EPS, progressively thickening over the days and securing the robustness of the biofilm, prevents the biofilm from dispersing in spite of the increased competition for oxygen.

\section{(ii) More biomass}

Hansen et al. (2007a, p. 534) noticed that "The productivity of the derived community was significantly greater than that of both the ancestral community and Acinetobacter alone .... This effect was attributable to enhanced productivity of $P$. putida and occurred despite a deleterious effect of $P$. putida on Acinetobacter-the species on which P. putida is reliant." Accordingly, even though the variation occurred in $P$. putida, not only P. putida biomass, but also the biofilm's biomass was increased.

\section{(iii) Different fitness}

There is no unique way to understand-and calculate-biofilms' fitness. In the literature, at least two different ways can be found. One way is to understand fitness as evolutionary fitness (i.e. differential reproductive success). In biofilms, evolutionary fitness may, in turn, be understood in two different ways: as a function of the fitness of the separate clonal lineages comprising the biofilm (O'Malley 2014, p. 112); or as the ability of a biofilm to seed new patches, which is expected to increase with its rate of dispersal. Another way is to understand biofilms' fitness as persistence, i.e. as the increase or decrease in the propensity to persist in response to pressures of the selective environment (Bouchard 2014). In the case under consideration, no matter how biofilms' fitness is understood, WTP and VP show differential fitness (in particular, WTP's fitness is higher than VP's fitness if understood as evolutionary fitness, while it is lower when understood as persistence).

Moving from phenotypic diversity to genetic diversity, it should be highlighted that the $P$. putida variant phenotype has been proved to be heritable and, when inoculated together with Acinetobacter into fresh biofilm flow chambers, the structure of the resulting community was similar to the newly formed one, VP, (and not to the ancestral one). Two independent mutations, responsible for the mantlelike phenotype, were identified in wapH (PP4943) - a gene involved in lipopolysaccharide biosynthesis. Accordingly, it may be argued that living in a biofilm also increased genetic biodiversity, both at the colony and the biofilm level, providing a new double-mutant genotype. It is normally assumed that this genetic variability 
occurred by random mutation processes, supplemented through natural selection in the local environment of the biofilm (Gross et al. 2012).

\subsection{Multispecies Biofilms as Drivers of Evolution}

"Evolutionary biologists often study the origin of biodiversity through the identification of the units at which evolution operates" (Bapteste et al. 2012, p. 18266). Throughout the history of evolutionary biology, bacteria have been often thought to follow different evolutionary rules not in line with those emphasised by the Modern Synthesis, which was modelled on the evolution of plants and animals, and according to which species or populations are considered to be the units of evolution and speciation the main process producing diversity. The peculiarity of prokaryotes was thought to be due mainly to their asexuality, that would prevent genuine speciation, to their hereditary mechanism not relying on specialised germ cells, and to the location of their genome, which is not in a cell nucleus. However, since prokaryotes have genes, display mutations, and show a process of vertical transmission, it is now commonly accepted that they fit the Modern Synthesis view of evolution (O'Malley 2014, Chap. 4). Yet, the genetic and phenotypic diversity we examined in the previous section cannot be accounted for in terms of species and speciation. Some recent works (see, in particular, Bapteste et al. 2012) have shown that many other processes rather than vertical descent contribute to generating diversity, namely processes that use genetic material from multiple sources, such as recombination, lateral gene transfer, and symbiosis. These processes produce evolutionary outcomes at different hierarchical levels, think for instance to the multiple symbiotic evolutionary origin of chloroplasts (Whatley and Whatley 1981). In the remaining we shall focus on the possibility of multispecies entities being units of selection along with "standard" organisms. If so, species, at least at the microbial level, might - quite unsurprisingly - prove not to be the most relevant units of biodiversity, and therefore speciation might not be the only process to be taken into account. Accordingly, on the one hand, a satisfactory account of biodiversity generation would ideally require to consider a much more varied set of evolutionary processes than just speciation; on the other hand, as we are going to suggest in the conclusion, species might sometimes not be the best targets of conservation actions. To put it in other words: if — as Huxley thought (1942: 126)_ “... bacteria have their own evolutionary rules", we may outline two main theoretical possibilities: either these rules set them apart from the Modern Synthesis' framework, requiring the existence of two different "modes" of evolution; or these rules enforce a better understanding, as well as an inclusion, in the modern synthesis' framework. We shall take this second stance, suggesting, moreover, that this would have positive consequences not only in our understanding of the processes producing biodiversity but also in shaping conservation actions. 


\subsubsection{The Origin of Biodiversity}

Those entities which are able to produce diversity, i.e. those entities capable of random heritable variations that eventually might increase fitness in the context of changing environments, are units of selection or evolutionary individuals, i.e. the objects that undergo the conditions identified by Darwin and formalised by Lewontin in his classic 1970 article (Lewontin 1970), namely phenotypic variation, differential fitness, heritability of fitness.

Lewontin was speaking of variation among individual organisms of a population or a species. Different individual organisms have different phenotypes, which have different rates of survival and reproduction. This difference in fitness must be somehow (notwithstanding the nature of the mechanism) heritable. When these three principles hold, a population or a species will undergo evolutionary change. Lewontin also pointed out that the logical skeleton of the Darwinian argument "turns out to be a powerful predictive system for changes at all levels of biological organization ... any entities in nature that have variation, reproduction, and heritability may evolve", provided that they satisfy the three principles. In compliance with Lewontin's suggestion, several entities have been proposed as possible "evolutionary individuals" in addition to individual organisms, both at lower (e.g. alleles) and higher (e.g. groups) levels of the hierarchy. ${ }^{3}$ Might some multispecies entities, and multispecies biofilms in particular, be evolutionary individuals?

Recently, this question caught the attention of philosophers of biology working on biological individuality (see Bouchard and Huneman 2013). This is because multispecies biofilms may be thought to show several characteristics that could make them similar to multicellular organisms such as us or other animals, i.e. the paradigmatic units of selection. Accordingly, it may be asked whether, by analogy, multispecies biofilms are amongst the units of selection, i.e. whether they are evolutionary individuals. According to Ereshefsly and Pedroso, the answer is positive, at least for some biofilms. They concede that evolutionary individuality can be a matter of degree and that not all biofilms are promising candidates to be evolutionary individuals: "the fact that some biofilms and other multispecies consortia exhibit more internal competition than others implies that some biofilms are more individual-like than other biofilms" (Ereshefsky and Pedroso 2015, p. 10131). According to these authors, there are 7 conditions a biological entity must meet to be said an evolutionary individual: (1) Having a high internal integration and being delineated from the environment; (2) Presenting division of labour and, relatedly, (3) coordination between the parts, and cooperation; (4) Bearing adaptations; (5) Transmitting traits between generations; (6) Having a reproductive bottleneck; and, relatedly, (7) Genetic homogeneity. In the next section, we will analyse these criteria in more detail with the aim of evaluating whether in comparison with heterotrophic bacterial

\footnotetext{
${ }^{3}$ Notice that while entities at a lower level (e.g. alleles) are more likely to satisfy the three conditions, whether there are evolutionary individuals at a higher level (groups, species, clades...) remains a matter of debate. The controversy concerns, in particular, reproduction-and, relatedly—heritability of fitness.
} 
biofilms, two kinds of multispecies autotrophic biofilms (i.e. microphytobenthos and biological soil crusts) meet the above criteria.

\subsubsection{Are MPB and BSCs Evolutionary Individuals?}

In this section, we go through the seven criteria for biofilms' evolutionary individuality (as they have been put forward by Ereshefsky and Pedroso 2015) to see whether they are fulfilled by MPB and BSCs, in comparison to paradigmatic bacterial biofilms, namely heterotrophic biofilms.

(1) High internal integration and delineation from the environment. This criterion is met by heterotrophic bacterial biofilms, since bacteria within a biofilm "act" as a whole, they communicate (for instance through quorum sensing) and exchange genes (more than planktonic bacteria). This is so mainly in virtue of the EPS, which packs them and keeps their parts together, contributing both to internal integration and delineation from the outside.

Also in MPB, the basic element of internal integrity is the EPS matrix that keeps cells together. The EPS matrix has been demonstrated to help congregate sediment particles, decrease erosion (Paterson and Black 1999) and probably facilitate the flux of carbon between other constituents of the biofilm, including embedded meiofauna (Middelburg et al. 2000). Likewise, in BSCs the EPS matrix plays a pivotal role in favouring the internal integration of the biofilm and its delineation from the environment. The integration is possibly more complex than in MPB and heterotrophic bacterial biofilms, due to the greater diversity which characterises BSCs. BSCs are usually constituted of cells coming from different higher-level taxa too, even in the early successional stages dominated by cyanobacteria, which may include green algae, heterotrophic bacteria, microfungi (Belnap et al. 2001 and references therein), and archaea (Soule et al. 2009). In later successional stages (e.g. bryophyte or lichen-dominated BSCs), integration will be looser as the intrusion of the macroscopic rooting structures of these organisms into the cyanobacterial biofilm is expected.

(2) Division of labour, and, relatedly, (3) Coordination and cooperation amongst parts. Functional specialisation, or division of labour, is common in most multicellular, colonial and social organisms, but it is far from ubiquitous (Simpson 2012). Quorum sensing is probably the main way bacteria coordinate; for instance, it regulates the amount of extracellular DNA that bacteria produce for their EPS, regulates gene expression, and triggers dispersal of the cells of biofilm. Eukaryotes are also known to utilise quorum sensing, as is the case with many fungal species and even social insects (Amin et al. 2012 and references therein). However, quorum sensing systems sensu stricto are not described for diatoms, albeit some mechanisms underlying diatom cell signalling have been discovered (Falciatore and Bowler 2002), and have been described in epilithic - i.e., colonizing bedrocks - cyanobacterial communities (Sharif et al. 2008), even though not in BSCs. However, it should be 
noticed that the studies of quorum sensing-like mechanisms in non-bacteria lag significantly behind those concerning bacteria.

Thanks to quorum sensing and analogous mechanisms, a division of labour can be frequently observed in heterotrophic bacterial biofilms, and it is often dependent on biofilms' internal architecture. For instance, there exist biofilms in which surface bacteria consume oxygen, intermediary bacteria convert sulphide into hydrogen sulfate, and bacteria living at greater depth cycles convert sulphate into sulphide. A further mark of individuality is cooperation among the parts (accompanied by low internal competition). It has been shown that bacteria within biofilms often excrete public goods (Czárán and Hoekstra 2009), i.e. exoproducts that are costly to produce but enhance the fitness of other cells, such as EPS or anti-biotic degradation compounds. This production is regulated through quorum sensing, and cheating is a phenomenon that frequently occurs (there are mutants which do not participate in the production of common goods while exploiting producers; or "liars", who produce the quorum sensing signal but not the exoproduct). Yet, cheaters are kept in check by "honest cooperators" through a variety of strategies (for instance, lateral gene transfer of genetic elements that infect non-cooperative mutants inducing them to produce the public good).

May division of labour and coordination and cooperation amongst parts be found in MPB and BSCs as well? In MPB, photosynthesis is mostly performed by diatoms, albeit cyanobacteria might contribute in a variable proportion (Vieira et al. 2013a). Transmission of organic carbon from diatoms to heterotrophic bacteria occurs in a short time (Middelburg et al. 2000). On the other hand, diatoms may benefit from the respiratory inorganic carbon released from sub-surface bacteria (Marques da Silva et al. 2017; Vieira et al. 2016). The relationship between these organisms, however, has been poorly characterised. Bacteria benefit from this relationship by gaining a source of readily available organic metabolites and a constant source of materials. Diatoms may gain specific organic compounds such as vitamins or growth factors from bacteria (Trick et al. 1984), but almost no evidence exists for the transfer of organic compounds from bacteria to phytoplankton. ${ }^{4}$ Recent research has underlined that obliged bacterial mutualism is a widespread phenomenon in nature (Morris et al. 2013). Therefore, it might be expected to be present also in the bacterial/diatom populations of microphytobenthos.

Putative division of labour on the diatom fraction of microphytobenthos may be related to the different cells' sizes of diatom species (Vieira et al. 2013b). Small cells present higher photosynthetic rates and therefore are better nutrient scavengers (Geider et al. 1986). On the other hand, large cell diatoms may be better adapted to variable environments (as is the case with intertidal mudflats) because of the increased capacity to store nutrients (Turpin and Harrison 1980).

As MPB, also BSCs comprise autotrophic (e.g. cyanobacteria and green algae) and heterotrophic (e.g. microfungi and archaea) organisms. Therefore, at this broad

\footnotetext{
${ }^{4}$ The recent controversy on the dependency of marine diatoms on symbiotic marine bacteria for the supply of vitamin B12 (a metabolite that diatoms do not synthesise, but which is essential for their metabolism, Croft et al. 2005; Droop 2007) highlights the complexity of this issue.
} 
level, a metabolic division of labour is present. In cyanobacterial mats (a different type of cyanobacteria-dominated communities), the supply of organic nitrogen is produced by a type of filamentous cyanobacteria. Filamentous cyanobacteria are also common in BSCs and therefore a similar role may be envisaged. To our knowledge, no further empirical evidence concerning division of labour in BSCs may be found in the literature. However, recent work (Kim et al. 2016) is likely to show that division of labour is a widespread phenomenon that rapidly emerges in bacterial communities.

(4) Bearing adaptations. Heterotrophic bacterial biofilms seem to meet also this criterion. Working with microphytobenthos, Jesus et al. (2009) showed that diatomdominated biofilms adapt to sediment conditions and tidal height. Sandy sediments exhibit photosynthetic pigments characteristic of a mixed cyanobacteria/diatom assemblage, showing an alternate seasonality, with cyanobacteria increasing in the summer and diatoms dominating in the spring. Furthermore, epipsammic (inhabiting sand) diatoms were smaller than epipelic (inhabiting mud) diatoms, suggesting an adaptation of the biofilm to the substrate, since these epipsammic non-motile diatoms live in close attachment to individual sand grains (Barnett et al. 2015). Also, epipelic biofilms showed evidence of being low light-acclimated and photoregulating by vertical migration movements, whereas epipsammic biofilms showed no vertical migration rhythms. Thus, the two types of diatom biofilms have distinct strategies to adapt to light intensity: epipelic diatoms use vertical migration to position themselves at the sediment depth of optimum light conditions, and epipsammic diatoms use specific photosynthetic and photoprotective pigments to photo-regulate. Cartaxana et al. (2015) found that elevated temperature led to an increase of cyanobacteria and a change in the relative abundance of major benthic diatom species present in the MPB community. On the contrary, no significant effect of elevated $\mathrm{CO}_{2}$ was detected on the relative abundance of cyanobacteria and major groups of benthic diatom species.

To our knowledge, direct experimental evidence for adaptation is absent for BSCs, but the wide variety of biological crusts covering ecologically different dry lands suggest considerable adaptability.

Thus, there is little doubt that criteria (1-2-3-4) are met by heterotrophic bacterial biofilms, even by multispecies biofilms (where internal competition is expected to be higher, even though it has been shown that quorum sensing works also interspecifically - Federle and Bassler 2003). Although less information is available, MPB biofilms, and even BSCs, are likely to meet these criteria. It is with heritabilityand hence reproduction - that things become more controversial. In a nutshell, the problem is that, even though biofilms have what may be called, metaphorically, a life-cycle by analogy with "standard" multicellular organisms like us, it is not clear to what extent the analogy can be stretched. Clarke (2016), for instance, objected that biofilms do not exhibit genuine life cycles, since the claims about life cycle stages can be conceptualised equally well in terms of ecological succession or changes in community structure. The colonisation of a new territory by founder species would correspond to phase 1 , their modification of the environment and the consequent secondary colonisation to phase 3 and 4 , seeding to phase 5 , etc. 
However, we do not find the objection entirely compelling, since it underestimates the role of the EPS (phase 2) for the cohesion and internal integrity of the entities under scrutiny. Yet we agree with Clarke that the issue is not an (entirely) empirical matter. Even though more data need to be collected, certain theoretical issues need to be settled in order to give a proper answer: can dispersion be seen as a form of reproduction? Do biofilms form lineages? Do they transmit faithfully acquired mutations to their "heirs"? The three further criteria help us tackle this sort of questions. Establishing whether biofilms, or more generally "multilineages clubs", ${ }^{5}$ can be counted amongst evolutionary individuals is, in part, a theoretical matter (which notion of reproduction - and which notion of inheritance-should we endorse?), and in part a matter of collecting empirical evidence-concerning reproduction, maintenance mechanisms, and fitness - which is still lacking.

(5) Transmitting traits between generations. This criterion has to do with Lewontin's heritability of fitness, i.e. the transmission of those biofilm-level traits that confer differential fitness to biofilms. We have discussed biofilms' fitness in the previous section, arguing that, at least in the case study that we considered, biofilms may have differential fitness and that the related trait can be transmitted. More generally, Ereshefsky and Pedroso (2015) report that specific genes within bacteria have been identified that transmit traits such as quorum sensing, the capacity to engage in specific metabolic interactions, aggregation patterns, cooperative behaviours, and the mechanisms underlying lateral gene transfer, as well as those for the production of EPS. No empirical data are available for microphytobenthos and biological soil crusts. Notice that the fulfillment of criterion 5 depends on availability of relevant empirical evidence, but also on which notion of reproduction is adopted. If a strict notion of reproduction-based on how we and other paradigmatic evolutionary individuals reproduce-is advocated, this and the two further criteria are unlikely to be met by biofilms.

(6) Reproductive bottleneck and, relatedly, (7) Genetic homogeneity. An individual has a reproductive bottleneck when its life cycle begins as a single cell (or a few cells) and that cell is replicated to form the cells of an individual. A reproductive bottleneck reduces competition among the cells of an individual (being the cells generated from the germline cells genetically homogeneous), and it favours the evolution of new traits allowing small mutational changes in the germline to have major effects on the descendants of the organism. Biofilms "reproducing" by dispersion/ aggregation and exchanging gene laterally lack a reproductive bottleneck sensu stricto, even though it might be argued that the same results of reproductive bottleneck may be obtained in other ways, for instance through an ecological bottleneck in which the size of the population decreases following environmental factors such as antimicrobial treatments. In this way, an ecological bottleneck reduces competition amongst the cells, increasing genetic relatedness (Ereshefsky and Pedroso 2015). As for genetic homogeneity, multispecies biofilms clearly lack it, being made

\footnotetext{
${ }^{5}$ Multilineages clubs are defined as "coalitions of entities that replicate in separate events and exploit some common genetic material that does not trace back to a single locus in a single last common ancestor of all the members" (Bapteste et al. 2012: 18268).
} 
of distinct lineages and being lateral gene transfer extremely common. Microphytobenthos and biological soil crusts, being multi-kingdom biofilms, are even less genetically homogeneous than biofilms made of bacteria only.

It is clear from this analysis, summarised in Table 9.1, that the possibility that not only multispecies heterotrophic bacterial biofilms but also MPB and BSCs are evolutionary individuals cannot be ruled out in principle. On the one hand, in order to provide a definite answer, further studies and more empirical data are needed (see for instance Van Colen et al. 2014). On the other hand, a theoretical reflection on the traditional (Modern-synthetic) way of conceiving the notions of reproduction and inheritance might be required. What matters for the purpose of the present contribu-

Table 9.1 Criteria for biofilms' evolutionary individuality applied to two autotrophic biofilms and to a paradigmatic (heterotrophic) bacterial biofilm

\begin{tabular}{|c|c|c|c|}
\hline & $\begin{array}{l}\text { Heterotrophic bacterial } \\
\text { biofilms }\end{array}$ & MPB & BSCs \\
\hline $\begin{array}{l}\text { Internal } \\
\text { integrity }\end{array}$ & EPS matrix & EPS matrix & EPS matrix \\
\hline $\begin{array}{l}\text { Division of } \\
\text { labour }\end{array}$ & $\begin{array}{l}\text { Depth-dependent metabolic } \\
\text { specialisation / production of } \\
\text { public goods }\end{array}$ & $\begin{array}{l}\text { Producers/consumers/specific } \\
\text { metabolite synthesis/ } \\
\text { carbohydrate } \\
\text { Synthesis vs. storage }\end{array}$ & $\begin{array}{l}\text { Producers/ } \\
\text { consumers } \\
\text { Putative } \\
\text { cyanobacterial } \\
\mathrm{N}_{2} \text { fixing }\end{array}$ \\
\hline $\begin{array}{l}\text { Coordination } \\
\text { amongst parts }\end{array}$ & $\begin{array}{l}\text { Quorum sensing; lateral gene } \\
\text { transfer }\end{array}$ & $\begin{array}{l}\text { Putative quorum sensing } \\
\text { analogs (pheromones, nitric } \\
\text { oxide) }\end{array}$ & $\begin{array}{l}\text { Putative } \\
\text { quorum sensing }\end{array}$ \\
\hline $\begin{array}{l}\text { Bearer of } \\
\text { adaptations }\end{array}$ & $\begin{array}{l}\text { Antibiotic } \\
\text { resistance / metabolic } \\
\text { interactions / sequential } \\
\text { aggregation }\end{array}$ & $\begin{array}{l}\text { Adaptation to sediment } \\
\text { granulometry, tidal height } \\
\text { and temperature and } \\
\text { dissolved inorganic carbon } \\
\text { (changes in population } \\
\text { structure - in diatom species } \\
\text { composition/size classes and } \\
\text { in diatom/cyanobacteria } \\
\text { ratio) }\end{array}$ & $\begin{array}{l}\text { No direct } \\
\text { empirical data } \\
\text { available }\end{array}$ \\
\hline $\begin{array}{l}\text { Heritable } \\
\text { adaptive traits }\end{array}$ & $\begin{array}{l}\text { Sensu lato possibly met, but } \\
\text { not sensu stricto; putative } \\
\text { specific genes transmitting } \\
\text { traits such as quorum sensing, } \\
\text { metabolic integration, } \\
\text { aggregation patterns, } \\
\text { cooperative behaviors, lateral } \\
\text { gene transfer, and production } \\
\text { of EPS }\end{array}$ & No empirical data available & $\begin{array}{l}\text { No empirical } \\
\text { data available }\end{array}$ \\
\hline $\begin{array}{l}\text { Reproductive } \\
\text { bottleneck }\end{array}$ & $\begin{array}{l}\text { Missing sensu stricto; but } \\
\text { possible "ecological } \\
\text { bottleneck" }\end{array}$ & No empirical data available & $\begin{array}{l}\text { No empirical } \\
\text { data available }\end{array}$ \\
\hline $\begin{array}{l}\text { Genetic } \\
\text { homogeneity }\end{array}$ & No & No & No \\
\hline
\end{tabular}


tion is that if they were discovered to be evolutionary individuals, they would be discovered to contribute to biodiversity in an even more fundamental way than by providing ecosystem services and genetic and phenotypic diversity, namely by being amongst the units at which evolution by natural selection operates.

\subsection{Conclusions}

In 1996, 10 years after the emerging of the term "biodiversity", a book entitled Species. The Units of Biodiversity appeared which has now become a reference for whoever aims at approaching the species problem (Claridge et al. 1997). The first line of the abstract of the first chapter, written by the editors of the book, i.e. M.F. Claridge, H.A. Dawah and M.R. Wilson, states that "From a practical viewpoint species are generally the units of biodiversity". The truth of the claim is taken for granted along all the chapter, where it is also stated that "species are normally the units of biodiversity and conservation", and it is added that the growing recognition of the importance of biodiversity, connected to its crisis, confers to the wrangle over the nature of species a wider significance. We believe that, also in the light of contemporary biological knowledge, our evolutionary understanding has partially changed, and that the claim that species are the units of biodiversity and conservation $^{6}$ is not so plain as it was thought and has partially changed since then. In particular, we think that entities such as multispecies biofilms may teach us some lessons, both from an evolutionary and a conservationist point of view.

Before looking at the lessons, let us "unpack" the claim that species are the units of biodiversity. This can be interpreted in at least three ways. The first is that species are important units of classification, i.e. that they are taxonomic units. The second is that species are important evolutionary units, i.e. they undergo evolutionary change. The third is that species are targets of conservation, i.e. they are conservation units.

First lesson, concerning species as taxonomic units. If understood in this way, the claim that species are the units of biodiversity is questionable at the microbial level because it is not clear whether species indeed exist when their constituent organisms reproduce asexually, as many microbes do (as already discussed in Claridge et al. 1997). As shown in Sect. 9.1, for instance, Ernst Mayr simply claimed that asexual organisms do not form species at all. Under the biological species concept, species are considered as quasi-discrete gene packages: organisms belonging to a species exchange genes amongst them but not with organisms belonging to other species. This is not the case for microbes, which exchange genes laterally across small and large phylogenetic distance. We have also seen that, at least operationally, the microbial world can be partitioned into species as well. However, this does not by any means guarantee that such operational taxonomic units correspond to "natural joints" as they might just be conventional categories made up by taxonomists, and it could be that, at least at the microbial level, other joints are more natu-

\footnotetext{
${ }^{6}$ See also Reydon, Chap. 8 in this volume.
} 
ral than species. As said, it is a fact that multispecies biofilms are the main mode of organisation of microbial life, and it is another fact that multispecies biofilms do exhibit new diversity, both at the genetic and at the phenotypic level.

Second lesson, concerning species as units of evolution (and organisms as evolutionary individuals, or units of selection). Traditionally species have been considered the units of biodiversity in evolutionary biology. The reason is simple: variation and selection range over various levels (macromolecules, cells, organisms...), resulting in evolution at higher levels, typically populations or species. In other words, (and taking a realistic stance towards species), species speciate, originating new species, i.e. increasing diversity and conferring the tree of life its shape. In the Modern-synthetic view, which is modelled on animals and plants, species are made of organisms, each of which belongs to its species and not to another, in an Aristotelian fashion. Organisms, the interactors, are the bearers of variations thatwhen inheritable - are transmitted through vertical descent. This picture has been questioned: there is growing evidence that vertical descent is not the only pattern of inheritance. Bapteste and his colleagues (2012), for instance, focus on what they call "introgressive descent", i.e. the process through which the genetic material of an evolutionary individual "propagates into different host structures and is replicated within these host structures" (Bapteste et al. 2012: 18266). On the basis of what we have discussed in this contribution, phenotypic variation and molecular change can arise in response to selection in multispecies entities, i.e. in entities which, by definition, do not belong to any species or belong to more than one species. Moreover, we have argued that the possibility that multispecies biofilms, both autotrophic and heterotrophic, are themselves units of selection cannot be ruled out. A question then arises, which requires further reflection: if multispecies biofilms, or other multilineages consortia, may be units of selection, which are the "corresponding" units of evolution?

Third lesson, concerning species as units of conservation. The centrality of species characterises a quite traditional approach to biodiversity conservation, which involves the maintenance of viable populations of certain species, such as, for instance, indicator species-those species that are thought to indicate the state of biodiversity of a certain area-or endangered species—-such as the ones listed in the IUCN red list. Several criticisms have been moved to this approach. In particular, a discrepancy between theory and practice has been highlighted: although "most conservationists claim to protect 'species', the conservation unit actually and practically managed is the individual population" (Casacci et al. 2013). Ideally, all individual populations of all species should be conserved; but conservation actions have to take into account our epistemic limits and economic constraints, and criteria for prioritisation are needed.

A way to proceed is to let evolutionary considerations indicate the direction in selecting targets for conservation actions. Notice that putting together biodiversity conservation and evolution strangely generates a sort of paradox: evolution implies change, and conservation implies keeping things as they are, or even bringing them back to their previous, allegedly pristine, state. However, conservation should also be understood in terms of preserving those ecological and evolutionary mechanisms 
necessary to promote natural dynamics (see Smith et al. 1993, and Vecchi and Mills, Chap. 12 in this volume), and it has been recognised that practical conservation decisions should be based on evolutionary considerations (Höglund 2009, Chap. 8.3; Eizaguirre and Baltazar-Soares 2014). The paradox dissolves through the distinction between two kinds of biodiversity conservation (Sarkar 2002). One is the analogue of ameliorative medicine and is practiced when we allow a species to decline and then try to recover it (the extreme case is the "emergency room", when we intervene only when a species is on the brink of extinction). The second kind is the analogue of preventive medicine, and it mainly consists in putting forward management procedures for the survival of the units of interest. What are such units? Sarkar (2002) suggested that conservationists should prioritise places. Places, in Sarkar's view, are individual places, specific regions on Earth "filled with the particular results of [their] individual story". More precisely, "preventive" conservation would consist in prioritisation of places for biodiversity value, whereas measuring biodiversity value would require the choice of surrogates. A different proposal is to focus on the Evolutionarily Significant Units (ESUs). The key idea of the ESUsbased approach is that, rather than preserving all phenotypic variants, it would be worthwhile to preserve those populations which "shows evidence of being genetically separate from other populations, and contributes substantially to the ecological or genetic diversity found within the species taxon as a whole" (Hey et al. 2003: 600). The premise is that as long as evolutionary processes are able to operate, their products, in particular specific adaptive phenotypes, can be replaced or recreated (Casetta and Marques da Silva 2015a).

Notwithstanding its merits (Casacci et al. 2013), the ESU-based approach is still conceptually species-centred (populations are population of species), i.e. it does not take into account multispecies entities. Yet, at the microbial level (and we have seen the importance of microbial biodiversity not only per se but also for general ecosystem functioning, in particular as far as biological soil crusts and microphytobentos are concerned), species might not be the most important units of biodiversity. Accordingly, an ESU-based approach would have the same limits as a species-based one.

However, we think that the idea of letting evolutionary consideration indicate the direction is worth following. In particular, we argued elsewhere (Casetta and Marques da Silva 2015a, b) that the species-based approach should be integrated by considering as (more) worthy of protection those entities that have evolutionary potential $^{7}$ (an indicator of the population's capacity to respond to environmental change, linking in this way environmental change and evolutionary dynamics). That suggestion makes even more sense in the case of the microbial world. In fact, we argued throughout our chapter that multispecies collectives such as biofilms might possess a certain propensity to evolve in response to environmental changes. We suggest that they should be recognised in biodiversity conservation accordingly and that, in conserving places, and in the perspective of preventive conservation actions, a priority should be given to those entities endowed with evolutionary potential.

${ }^{7}$ See also Minelli, Chap. 11, and Vecchi and Mills, Chap. 12, in this volume. 
Such entities are traditionally thought to be species and populations, but, on the basis of what we have discussed, evolutionary potential might be a property of multispecies communities as well.

In sum, evolutionary potential is a crucial feature to be taken into account in conservation actions once that conservation is understood not only as ameliorative medicine but also as preventive medicine. Taking into account evolutionary potential would enlarge the focus of conservation actions from species to a larger number of entities (i.e. certain species and populations, certain multispecies communities, and possibly certain ecosystems as well), and it might meet the need of prioritisation that economic constraints dictate to biodiversity conservation practice while going beyond a mere species-based or population-based approach.

Acknowledgements Though this contribution has been conceived and discussed together, Elena Casetta is the author of Sects. 9.1, 9.2 and 9.4, while Jorge Maques da Silva is the author of Sect. 9.3. We are thankful to Philippe Huneman, Sandro Minelli, and Davide Vecchi for their useful comments on a previous version of this chapter. This work was funded by the Fundação para a Ciência e a Tecnologia (R\&D project Biodecon, ref. PTDC/IVC-HFC/1817/2014) and by the European Union's Fp7 Research and Innovation Programme under the Marie Sklodowska-Curie grant agreement No $609402-2020$ (Train to Move).

\section{References}

Achtman, M., \& Wagner, M. (2008). Microbial diversity and the genetic nature of microbial species. Nature Reviews Microbiology, 6, 431-440.

Adessi, A., Cruz de Carvalho, R., De Philippis, R., Branquinho, C., \& Marques da Silva, J. (2018). Microbial extracellular polymeric substances improve water retention in dryland biological soil crusts. Soil Biology and Biochemistry, 116, 67-69.

Amin, S. A., Parker, M. S., \& Armbrust, E. V. (2012). Interactions between diatoms and bacteria. Microbiology and Molecular Biology Reviews, 76(3), 667-684.

Angus, A. A., \& Hirsch, A. M. (2013). Biofilm formation in the rhizosphere: Multispecies interactions and implications for plant growth. In F. J. de Bruijn (Ed.), Molecular microbial ecology of the rhizosphere (Vol. 2, pp. 703-712). Hoboken:Wiley. https://doi.org/10.1002/9781118297674.

Bapteste, E., Lopez, P., Bouchard, F., Baquero, F., McInerney, J. O., \& Burian, R. M. (2012). Evolutionary analyses of non-genealogical bonds produced by introgressive descent. PNAS, 109(45), 18266-18272.

Barnett, A., Méléder, V., Blommaert, L., Lepetit, B., Gaudin, P., Vyverman, W., Sabbe, K., Dupuy, C., \& Lavaud, J. (2015). Growth form defines physiological photoprotective capacity in intertidal benthic diatoms. The ISME Journal, 9, 32-45.

Bell, T., Gessner, M. O., Griffiths, R. I., McLaren, J., Morin, P. J., van der Heijden, M., \& van der Putten, W. (2009). Microbial biodiversity and ecosystem functioning under controlled conditions and in the wild. In S. Naeem, D. E. Bunker, A. Hector, M. Loreau, \& C. Perrings (Eds.), Biodiversity, ecosystem functioning, and human wellbeing: An ecological and economic perspective (pp. 121-133). Oxford: Oxford University Press.

Belnap, J., Kaltenecker, J. H., Rosentreter, R., Williams, J., Leonard, S., \& Eldridge, D. (2001). Biological soil crusts: Ecology and management. In P. Paterson (Ed.), Technical reference (pp. 1730-1732). Denver: United States Department of Interior.

Besemer, K. (2015). Biodiversity, community structure and function of biofilms in stream ecosystems. Research in Microbiology, 166, 774-781. 
Bogino, P. C., Oliva Mde, L., Sorroche, F. G., \& Giordano, W. (2013). The role of bacterial biofilms and surface components in plant-bacterial associations. International Journal of Molecular Sciences, 14, 15838-15859.

Bouchard, F. (2014). Ecosystem evolution is about variation and persistence, not populations and reproduction. Biological Theory, 9(4), 382-391.

Bouchard, F., \& Huneman, P. (Eds.). (2013). From groups to individuals. Evolution and emerging individuality. Cambridge, MA: MIT Press.

Cabarkapa, I., Levic, J., \& Djuragic, O. (2013). Biofilm. In A. Méndez-Vilas (Ed.), Microbial pathogens and strategies for combating them: Science, technology and education (Vol. I, pp. 42-52). Badajoz: Formatex Research Center.

Cartaxana, P., Vieira, S., Ribeiro, L., Rocha, R. J. M., Cruz, S., Calado, R., \& Marques da Silva, J. (2015). Effects of elevated temperature and $\mathrm{CO} 2$ on intertidal microphytobenthos. BMC Ecology, 15, 10.

Casacci, L. P., Barbero, F., \& Balletto, E. (2013). The "Evolutionarily Significant Unit" concept and its applicability in biological conservation. Italian Journal of Zoology, 1-12. https://doi. org/10.1080/11250003.2013.870240.

Casetta, E., \& Marques da Silva, J. (2015a). Facing the big sixth. From prioritizing species to conserving biodiversity. In E. Serrelli \& N. Gontier (Eds.), Macroevolution - Explanation, interpretation, evidence (pp. 377-403). Berlin: Springer.

Casetta, E., \& Marques da Silva, J. (2015b). Biodiversity surgery. Some epistemological challenges in facing extinction. Axiomathes, 25(3), 239-251.

Claridge, M. F., Dawah, H. A., \& Wilson, M. R. (Eds.). (1997). Species: The units of biodiversity. London: Chapman \& Hall.

Clarke, E. (2016). Levels of selection in biofilms: Multispecies biofilms are not evolutionary individuals. Biology and Philosophy, 31, 191-212.

Costanza, R., d'Arge, R., de Groot, R., Farberk, S., Grasso, M., Hannon, B., Limburg, K., Naeem, S., O’Neill, R. V., Paruelo, J., Raskin, R. G., Suttonkk, P., \& van den Belt, M. (1997). The value of the world's ecosystem services and natural capital. Science, 387, 253-260.

Croft, M. T., Lawrence, A. D., Raux-Deery, E., Warren, M. J., \& Smith, A. G. (2005). Algae acquire vitamin B12 through a symbiotic relationship with bacteria. Nature, 438, 90-93.

Czárán, T., \& Hoekstra, R. F. (2009). Microbial communication, cooperation and cheating: Quorum sensing drives the evolution of cooperation in bacteria. PLoS One, 4(8), e6655. https:// doi.org/10.1371/journal.pone.0006655.

Dobzhansky, T. (1937). Genetics and the origin of species. New York: Columbia University Press.

Doolittle, F., \& Papke, T. (2006). Genomics and the bacterial species problem. Genome Biology, 7, 116.1-116.7.

Droop, M. R. (2007). Vitamins, phytoplankton and bacteria: Symbiosis or scavenging? Journal of Plankton Research, 29(2), 107-113.

Eizaguirre, C., \& Baltazar-Soares, M. (2014). Evolutionary conservation-evaluating the adaptive potential of species. Evolutionary Applications, 7(9), 963-967.

Eldridge, D. J., \& Leys, J. F. (2003). Exploring some relationships between biological soil crusts, soil aggregation and wind erosion. Journal of Arid Environments, 53, 457-466.

Elias, S., \& Banin, E. (2012). Multi-species biofilms: Living with friendly neighbors. FEMS Microbiology Reviews, 36(5), 990-1004.

Ereshefsky, M. (2010). Microbiology and the species problem. Biology and Philosophy, 25(4), 553-568.

Ereshefsky, M., \& Pedroso, M. (2015). Rethinking evolutionary individuality. PNAS, 112(33), 10126-10132.

Falciatore, A., \& Bowler, C. (2002). Revealing the molecular secrets of marine diatoms. Anпиal Review of Plant Biology, 53, 109-130.

Falkowski, P. G., Fenchel, T., \& Delong, E. F. (2008). The microbial engines that drive Earth's biogeochemical cycles. Science, 320, 1034-1039. 
Federle, M. J., \& Bassler, B. L. (2003). Interspecies communication in bacteria. Journal of Clinical Investigation, 112(9), 1291-1299. https://doi.org/10.1172/JCI200320195.

Geider, R. J., Osborne, B. A., \& Raven, J. A. (1986). Growth, photosynthesis and maintenance metabolic cost in the diatom Phaeodactylum tricornutum at very low light levels. Journal of Phycology, 22, 9-48.

Gross, R., Schmid, A., \& Buehler, K. (2012). Catalytic biofilms: A powerful concept for future bioprocesses. In G. Lear \& G. D. Lewis (Eds.), Microbial biofilms: Current research and applications (pp. 193-222). Cardiff: Caister Academic Press.

Hansen, S. K., Rainey, P. B., Haagensen, J. A. J., \& Molin, S. (2007a). Evolution of species interactions in a biofilm community. Nature Letters, 445(1), 533-536.

Hansen, S. K., Haagensen, J. A. J., Gjermansen, M., Jorgensen, T. M., Tolker-Nielsen, T., \& Molin, S. (2007b). Characterization of a Pseudomonas putida rough variant evolved in a mixed-species biofilm with Acinetobacter sp strain C6. Journal of Bacteriology, 189(13), 4932-4943.

Hey, J., Waples, R. S., Arnold, M. L., Butlin, R. K., \& Harrison, R. G. (2003). Understanding and confronting species uncertainty in biology and conservation. Trends in Ecology \& Evolution, 18(11), 597-603.

Höglund, J. (2009). Evolutionary conservation genetics. Oxford: Oxford University Press.

Huxley, J. (1942). Evolution: The modern synthesis. London: George Allen \& Unwin.

Jesus, B., Brotas, V., Ribeiro, L., Mendes, C. R., Cartaxana, P., \& Paterson, D. M. (2009). Adaptations of microphytobenthos assemblages to sediment type and tidal position. Continental Shelf Research, 29, 1624-1634.

Kaplan, J. B. (2010). Biofilm dispersal: Mechanisms, clinical implications, and potential therapeutic uses. Journal of Dental Research, 89(3), 205-218.

Kim, W., Levy, S. B., \& Foster, K. (2016). Rapid radiation in bacteria leads to a division of labour. Nature Communications, 7, 10508. https://doi.org/10.1038/ncomms10508.

Kjelleberg, S. (1993). Starvation in bacteria. New York: Plenum.

Lewontin, R. (1970). The units of selection. Annual Review of Ecology and Systematics, 1, 1-18.

Lugtenberg, B. J. J., Malfanova, N., Kamilova, F., \& Berg, G. (2013). Plant growth promotion by microbes. In F. J. de Bruijn (Ed.), Molecular microbial ecology of the rhizosphere (Vol. 2, pp. 561-574). Hoboken: Wiley. https://doi.org/10.1002/9781118297674.

Macintyre, H. L., Geider, R. J., \& Miller, D. C. (1996). Microphytobenthos: The ecological role of the "secret garden" of unvegetated, shallow-water marine habitats. I. Distribution, abundance and primary production. Estuaries, 19, 186-201.

Marques da Silva, J. (2015). Reconciling science and nature by means of the aesthetical contemplation of natural diversity. Rivista di Estetica, 59(2), 93-113.

Marques da Silva, J., Cruz, S., \& Cartaxana, P. (2017). Inorganic carbon availability in benthic diatom communities: Photosynthesis and migration. Philosophical Transactions of the Royal Society London B, 372, 20160398.

Mayr, E. (1970). Populations, species, and evolution. Cambridge, MA: Harvard University Press.

Middelburg, J. J., Barranguet, C., Boschker, H. T. S., Herman, P. M. J., Moens, T., \& Heip, C. H. R. (2000). The fate of intertidal microphytobenthos carbon: An in situ ${ }^{13} \mathrm{C}$-labeling study. Limnology and Oceanography, 45(6), 1224-1234.

Morris, B. E. L., Henneberger, R., Huber, H., \& Moissl-Eichinger, C. (2013). Microbial syntrophy: Interaction for the common good. FEMS Microbiology Reviews, 37, 384-406.

Nadell, C. D., Drescher, K., \& Foster, K. R. (2016). Spatial structure, cooperation and competition in biofilms. Nature Reviews Microbiology, 14, 589-600.

O’Malley, M. (2014). Philosophy of microbiology. Cambridge: Cambridge University Press.

Paterson, D. M. (1986). The migratory behaviour of diatom assemblages in a laboratory tidal microecosystem examined by low temperature scanning electron microscopy. Diatom Research: The Journal of the International Society for Diatom Research, 1, 227-239.

Paterson, D. M., \& Black, K. M. (1999). Water flow, sediment dynamics and benthic biology. Advances in Ecological Research, 29, 155-193. 
Qaim, M., \& Zilberman, D. (2003). Yield effects of genetically modified crops in developing countries. Science, 299(5608), 900-902.

Richards, R. (2010). The species problem. New York: Cambridge University Press.

Roesch, L. F., Fulthorpe, R. R., Riva, A., Casella, G., Hadwin, A. K., Kent, A. D., Daroub, S. H., Camargo, F. A., Farmerie, W. G., \& Triplett, E. W. (2007). Pyrosequencing enumerates and contrasts soil microbial diversity. The ISME Journal, 1(4), 283-290.

Round, F. E., \& Palmer, J. D. (1966). Persistent, vertical-migration rhythms in benthic microflora. II. Field and laboratory studies on diatoms from the banks of the river Avon. Journal of the Marine Biological Association of the UK, 46, 191-214.

Sarkar, S. (2002). Defining 'biodiversity'; Assessing biodiversity. The Monist, 85(1), 131-155.

Sauer, K., Camper, A. K., Ehrlich, G. D., Costerton, J. W., \& Davies, D. G. (2002). Pseudomonas aeruginosa displays multiple phenotypes during development as a biofilm. Journal of Bacteriology, 184, 1140-1154.

Sharif, D., Gallon, J., Smith, C. J., \& Dudley, E. (2008). Quorum sensing in Cyanobacteria: N-octanoyl-homoserine lactone release and response, by the epilithic colonial cyanobacterium Gloeothece PCC6909. The ISME Journal, 2, 1171-1182.

Simpson, C. (2012). The evolutionary history of division of labour. Proceedings of the Royal Society B, 279, 116-121.

Smith, T. B., Bruford, M. W., \& Wayne, R. K. (1993). The preservation of process: The missing element of conservation programs. Biodiversity Letters, 1(6), 164-167.

Soule, T., Anderson, I. J., Johnson, S. L., Bates, S. T., \& Garcia-Pichel, F. (2009). Archaeal populations in biological soil crusts from arid lands in North America. Soil Biology \& Biochemistry, 41, 2069-2074.

Stal, L. J., \& de Brouwer, J. F. C. (2003). Biofilm formation by benthic diatoms and their influence on the stabilization of intertidal mudflat. In J. Rullkötter (Ed.), BioGeoChemistry of tidal flats. Proceedings of a workshop at the Hanse Institute of Advanced Study, May 14-17, Delmenhorst, Germany (pp. 109-111). Wilhelmshaven: Forschungszentrum Terramare.

Stoodley, P., Sauer, K., Davies, D. G., \& Costerton, J. W. (2002). Biofilms as complex differentiates communities. Annual Review of Microbiology, 56, 187-209.

Trick, C. G., Anderson, R. J., \& Harrison, P. J. (1984). Environmental factors influencing the production of an antibacteria Jmetabolite from a marine dinoflagellate, Prorocentrum minimum. Canadian Journal of Fisheries and Aquatic Sciences, 41, 423-432.

Turpin, D. H., \& Harrison, P. J. (1980). Cell size manipulation in natural marine, planktonic, diatom communities. Canadian Journal of Fisheries and Aquatic Sciences, 37, 1193-1195.

Underwood, G. J. C., \& Kromkamp, J. (1999). Primary production by phytoplankton and microphytobenthos in estuaries. Advances in Ecological Research, 29, 93-153.

Van Colen, C., Underwood, G. J. C., Serôdio, J., \& Paterson, D. M. (2014). Ecology of intertidal microbial biofilms: Mechanisms, patterns and future research needs. Journal of Sea Research, $92,2-5$.

Van der Heijden, M. G. A., Bardgett, R. D., \& van Straalen, N. M. (2008). The unseen majority: Soil microbes as drivers of plant diversity and productivity in terrestrial ecosystems. Ecology Letters, 11, 296-310.

Vieira, S., Ribeiro, L., Jesus, B., Cartaxana, P., \& Marques da Silva, J. (2013a). Photosynthesis assessment in microphytobenthos with conventional and imaging pulse amplitude modulation fluorometry. Photochemistry and Photobiology, 89, 97-102.

Vieira, S., Ribeiro, L., Marques da Silva, J., \& Cartaxana, P. (2013b). Effects of short-term changes in sediment temperature on the photosynthesis of two intertidal microphytobenthos communities. Estuarine, Coastal and Shelf Science, 119, 112-118. https://doi.org/10.1016/j. ecss.2013.01.001.

Vieira, S., Cartaxana, P., Máguas, C., \& Marques da Silva, J. (2016). Photosynthesis in estuarine intertidal microphytobenthos is limited by inorganic carbon availability. Photosynthesis Research, 128, 85-92. https://doi.org/10.1007/s11120-015-0203-0. 
Vlamakis, H., Aguilar, C., Losick, R., \& Kolter, R. (2008). Control of cell fate by the formation of an architecturally complex bacterial community. Genes \& Development, 22, 945-953.

Whatley, J. M., \& Whatley, F. R. (1981). Chloroplast evolution. New Phytologist, 87, 233-247.

Whitman, W. B., Coleman, D. C., \& Wiebe, W. J. (1998). Prokaryotes: The unseen majority. Proceedings of the National Academy of Sciences of the United States of America, 95, 6578-6583.

Williamson, K. S., Richards, L. A., Perez-Osorio, A. C., Pitts, B., McInnerney, K., Stewart, P. S., \& Franklin, M. J. (2012). Heterogeneity in Pseudomonas aeruginosa biofilms includes expression of ribosome hibernation factors in the antibiotic-tolerant subpopulation and hypoxiainduced stress response in the metabolically active population. Journal of Bacteriology, 194(8), 2062-2073.

Woods, P. M. (2000). Biodiversity and democracy: Rethinking society and nature. Vancouver: University of British Columbia Press.

Open Access This chapter is licensed under the terms of the Creative Commons Attribution 4.0 International License (http://creativecommons.org/licenses/by/4.0/), which permits use, sharing, adaptation, distribution and reproduction in any medium or format, as long as you give appropriate credit to the original author(s) and the source, provide a link to the Creative Commons licence and indicate if changes were made.

The images or other third party material in this chapter are included in the chapter's Creative Commons licence, unless indicated otherwise in a credit line to the material. If material is not included in the chapter's Creative Commons licence and your intended use is not permitted by statutory regulation or exceeds the permitted use, you will need to obtain permission directly from the copyright holder.

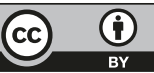

